\title{
TWO CASES OF HYDRAZINE HYDRATE DERMATITIS WITHOUT SYSTEMIC INTOXICATION
}

\author{
BY
}

\author{
DARRELL M. EVANS \\ From the United Kingdom Atomic Energy Authority
}

(RECEIVED FOR PUBLICATION SEPTEMBER 26, 1958)

Two patients exposed to hydrazine hydrate suffered contact dermatitis on the fingers of both hands, but remained free from systemic intoxication. The case histories are given, and a simple test is described for the detection of hydrazine both on the skin and in the atmosphere.

Hydrazine hydrate is an irritant which readily vaporizes. The irritant effects are not immediately noticeable. They develop gradually over several hours (Byrkit and Michalek, 1950). The local effects are inflammation of the skin and of the mucous membranes of the upper respiratory tract and eyes. Krop (1954) reports the occurrence of hydrazine dermatitis. Individual susceptibility to dermatitis varies. A specific sensitization may develop from short or long contact with many substances (Sequeira, Ingram, and Brain, 1947; Comstock, Lawson, Greene, and Oberst, 1954).

Systemic intoxication may follow absorption into the body by inhalation, by ingestion, or through the skin. Hydrazine is a liver poison, causing acute fatty degeneration and destruction of red blood cells (Sax, 1957; Comstock, et al., 1954). The latter effect is disputed by some authors, but phenylhydrazine causes haemolysis of mature red blood cells and is used for treating cases of polycythaemia vera. A slight haemorrhagic pulmonary oedema may develop. The earliest symptoms in man may be anorexia and loss of weight, thus acting as a warning sign of an impending health hazard (Comstock et al., 1954). No permanent ill effects are known to have occurred after recovery from a severe attack of poisoning.

The maximum allowable concentration of hydrazine hydrate is tentatively stated by the American Conference of Governmental Industrial Hygienists to be 1 p.p.m. in air (Sax, 1957).

\section{Properties}

Aqueous solutions of hydrazine are basic and act as a reducing agent. Hydrazine can be employed to reduce compounds of metals such as silver, gold, and copper to the metallic state. It is oxidized slowly in air at room temperatures (about $0.01 \%$ per hour), and reacts very readily with oxidizing compounds such as hydrogen peroxide, chlorates, and nitric acid. If hydrazine is allowed to come into contact with oxidizing acids it may decompose with explosive violence. Storage in an inert atmosphere reduces the tendency to oxidation, a fact which is particularly important to remember in quantitative analytical work. It decomposes catalytically in the presence of some active metals and oxides. As hydrazine attacks cork, rubber, and certain organic substances, contact with these must be avoided during storage. It can be stored in glass or polythene containers.

\section{Industrial Uses}

Hydrazine is used in the following processes (Audrieth, Mohr, and Mohr, 1951; Audrieth and Ogg, 1951):-Manufacture of certain drugs, such as isonicotinic acid and dye intermediates, and of certain plastic and rubber products; in rocket fuel; in photography; in the manufacture of certain insecticides, fungicides, and preservatives; in certain flux compositions in order to clean the metal and prevent further oxidation of the metallic surface; in boiler feed water to prevent corrosion as it removes dissolved oxygen; in the silvering of mirrors and plastics; as an agent for treating textiles, e.g., uncrushable cloth; maleic hydrazide is used to retard plant growth.

\section{Case Histories}

Case 1 reported the day after he had used hydrazine hydrate when an irritating rash had developed. The distribution was on the dorsum and between the fingers of both hands. At this stage the palmar aspect was 
unaffected. The rash consisted mainly of small vesicles, some of which had ruptured and small crusts had developed. There were fissures on two fingers. He stated that this was the fourth time he had developed dermatitis after using hydrazine hydrate. He was given an antipruritic lotion ("surfathesin"). He went away on holiday and was next seen 10 days later, when he had an exfoliative dermatitis with multiple fissures on the fingers of both hands. He was then treated with an antipruritic ointment ("eurax") and the condition improved. Unfortunately, soon after the dermatitis had healed he unwittingly came into contact with hydrazine hydrate again. Within seven hours his fingers were irritating and next morning he had developed a recurrence of the rash on his fingers.

Case 2 was seen two or three weeks after the onset of the rash, when several blisters were seen on the fingers. There had been a history of using hydrazine hydrate just before developing the rash. He had had a similar condition previously, also after contact with hydrazine hydrate.

Neither of the cases mentioned showed any signs of systemic intoxication. They had both been in contact with hydrazine hydrate at irregular intervals for about five months before developing a rash for the first time.

Rapid Test for Detecting Hydrazine

An aqueous solution of hydrazine reacts with $1.5 \%$ alcoholic solution of picryl chloride in neutral or mildly alkaline solution to form a pink violet colour. The test is reported to be effective in concentrations down to 1:400,000 (Kalberg and Cherkesov, 1951; Chemical Abstracts, 1952).

This test was modified in order to detect the presence of hydrazine on the fingers. A filter paper was impregnated with $1.5 \%$ alcoholic solution of picryl chloride and the fingers were pressed onto the paper, which was then held in the vapour over an unstoppered bottle of ammonia. The places which had been in contact with the skin changed from yellow to blue, sometimes being encircled by a red ring, if hydrazine was present.

This test was positive in Cases 1 and 2 and in another man who had worked with hydrazine hydrate but did not develop dermatitis. The latter man and Case 1 still showed a positive result to this skin test one day after contact in spite of normal washing. It seems likely that the reasons for hydrazine persisting on the fingers are, first, that there are no readily reducible substances in the epidermis, and secondly, being a basic substance, hydrazine penetrates the epidermal cells and is not readily washed off.

Hydrazine vapour can be detected in the air by placing test papers of picryl chloride at suitable points in the laboratory. A colour change occurs as described above. For greater sensitivity to low concentrations of hydrazine vapour a standardized gas flow absorption method using the same reagent can be used.

\section{Precautions in Handling Hydrazine}

These observations confirm the need to keep hydrazine confined so far as is possible, and when it is being used there should be adequate ventilation. Gloves and goggles may be required for repeated handling. Lanoline should be used to protect the exposed skin surfaces. Eye wash bottles filled with fresh water should be readily at hand.

When dealing with large quantities of hydrazine breathing apparatus is required and a bath of fresh tepid water should be readily available for rapid decontamination of the skin.

I wish to thank the United Kingdom Atomic Energy Authority for permission to publish this paper. I would also like to thank Messrs. K. T. B. Scott and S. W. Maxted for their advice on the chemistry of hydrazine.

\section{REFERENCES}

Audrieth, L. F., and Ogg, B. A. (1951). Chemistry of Hydrazine. Chapman \& Hall, London

Mohr, P. H., and Mohr, E. B. (1951). In Encyclopedia of Chemical Technology, ed. R. E. Kirk and D. F. Othmer, Vol. 7, p. 575. Interscience Encyclopedia, Inc., New York. Byrkit, G. D., and Michalek, G. A. (1950). Industr. Engng Chem., 42,1862 .

Chemical Abstracts (1952), 46, 2960 C.

Chemical Abstracts (1952), 46, 2960 C.
Comstock. C. C.. Lawson, L. H., Greene, E. A., and Oberst, F. W. (1954). A.M.A. Arch. industr. Hyg., 10, 476

Kalberg and Cherkesov (1951). Zhur. anal. Khim., 6, 347

Krop, S. (1954). A.M.A. Arch. industr. Hyg., 9, 199.

Sax, N. I. (1957. Dangerous Properties of Industrial Materials, p. 761. Reinhold, New York.

Sequeira, J. H.. Ingram, J. T., and Brain, R. T. (1947). Diseases of the Skin, 5th ed., p. 350. Churchill, London. 